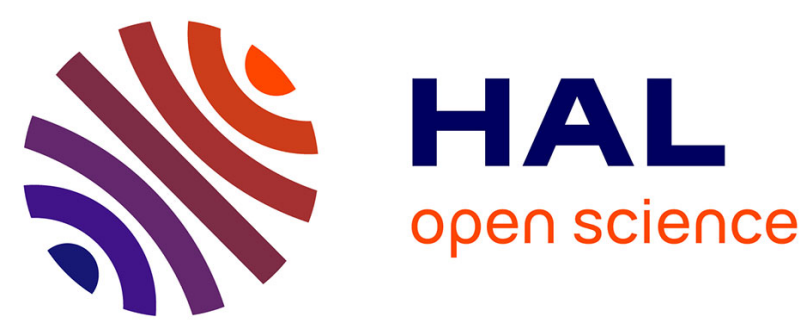

\title{
Appropriateness of early breast cancer management in relation to patient and hospital characteristics: a population based study in Northern Italy
}

R. Rosato, C. Sacerdote, E. Pagano, D. Cuonzo, I. Baldi, R. Bordon, A. Ponti, O. Bertetto, N. Segnan, F. Merletti, et al.

\section{To cite this version:}

R. Rosato, C. Sacerdote, E. Pagano, D. Cuonzo, I. Baldi, et al.. Appropriateness of early breast cancer management in relation to patient and hospital characteristics: a population based study in Northern Italy. Breast Cancer Research and Treatment, 2008, 117 (2), pp.349-356. 10.1007/s10549-008-0252-6 . hal-00535319

\section{HAL Id: hal-00535319 \\ https://hal.science/hal-00535319}

Submitted on 11 Nov 2010

HAL is a multi-disciplinary open access archive for the deposit and dissemination of scientific research documents, whether they are published or not. The documents may come from teaching and research institutions in France or abroad, or from public or private research centers.
L'archive ouverte pluridisciplinaire HAL, est destinée au dépôt et à la diffusion de documents scientifiques de niveau recherche, publiés ou non, émanant des établissements d'enseignement et de recherche français ou étrangers, des laboratoires publics ou privés. 


\title{
Appropriateness of early breast cancer management in relation to patient and hospital characteristics: a population based study in Northern Italy
}

\author{
R. Rosato $\cdot$ C. Sacerdote $\cdot$ E. Pagano $\cdot$ D. Di Cuonzo $~$ \\ I. Baldi $\cdot$ R. Bordon - A. Ponti - O. Bertetto . \\ N. Segnan $\cdot$ F. Merletti $\cdot$ P. Vineis $\cdot$ G. Ciccone
}

Received: 14 July 2008/Accepted: 10 November 2008/Published online: 3 December 2008

(C) Springer Science+Business Media, LLC. 2008

\begin{abstract}
Administrative data may provide valuable information for monitoring the quality of care at population level and offer an efficient way of gathering data on individual patterns of care, and also to shed light on inequalities in access to appropriate medical care. The aim of the study was to investigate the role of patient and hospital characteristics in the initial treatment of early breast cancer using administrative data. Incident breast cancer patients were identified from hospital discharge records and linked to the radiotherapy outpatient database during 2000-2004 in the Piedmont region of Northwestern Italy. Women treated with breast-conserving surgery followed by radiotherapy (BCS $+\mathrm{RT}$ ) were compared to those treated with BCS without radiotherapy (BCS w/o RT) or mastectomy using multinomial logistic regression models. Out of 16,022 incident cases, $46.2 \%$ received $\mathrm{BCS}+\mathrm{RT}, 20.3 \%$ received $\mathrm{BCS}$ w/o RT, and $33.5 \%$ received a mastectomy. Compared to $\mathrm{BCS}+\mathrm{RT}$, the factors associated with BCS w/o RT were: increased age $(\mathrm{OR}=1.54 ; 95 \% \mathrm{CI}=1.29-1.85$, for ages $70-79$ vs. $<50)$, being unmarried $(1.24 ; 1.13-1.36)$, presence of
\end{abstract}

\section{R. Rosato}

Department of Psychology, University of Torino, Torino, Italy

R. Rosato $(\bowtie) \cdot$ C. Sacerdote $\cdot$ E. Pagano - D. Di Cuonzo I. Baldi · R. Bordon · A. Ponti - N. Segnan · F. Merletti · P. Vineis - G. Ciccone

Unit of Cancer Epidemiology, AOU S. Giovanni Battista, CPO

Piemonte, CeRMS, University of Torino, Torino, Italy

e-mail: rosalba.rosato@unito.it

O. Bertetto

Agency for Regional Health Service, Regione Piemonte, Italy

P. Vineis

Department of Epidemiology and Public Health, Imperial

College London, London, UK co-morbidities $(1.32 ; 1.10-1.58)$, being treated at hospitals with low surgical volume $(1.31 ; 1.07-1.60$ for hospitals with less than 50 vs. $\geq 150$ interventions/year), and living far from radiotherapy facilities $(1.75 ; 1.39-2.20$ for those at a distance of $>45 \mathrm{~min}$ ). These same factors were also associated with mastectomy. During the 5-year period observed, there was a trend of reduced probability of receiving a mastectomy $(0.70 ; 0.56-0.88$ for 2004 vs. 2000). The presence or absence of nodal involvement was positively associated with mastectomy $(2.28 ; 1.83-2.85)$ and negatively associated with BCS w/o RT $(0.65$; $0.56-$ 0.76). After adjustment for potential confounders, education level did not show any association with the type of treatment. Social and geographical factors, in addition to hospital specialization, should be considered to reduce inappropriateness of care for breast cancer.

Keywords Breast surgery - Administrative data . Radiotherapy · Inequalities heath care

\section{Introduction}

Monitoring the quality of care at a population level using administrative data may offer several opportunities for improvement [1]. In particular, these data can provide useful information if key services are over- or under-used and if the linkage between different databases may lead to an efficient way of gathering data on individual patterns of care [2]. These data can also shed light on inequalities in access to appropriate medical care.

In the Piedmont region of Northwestern Italy (population 4.25 million), the development and implementation of evidence-based clinical practice guidelines for most common cancers, including breast cancer [3], were tracked by 
an evaluation project to assess adherence with key recommendations. Breast cancer has one of the most extensive scientific literatures on quality of care [4] and has demonstrated an association between pattern of care and outcome [5]. In the case of early breast cancer, it is well known that, though conservative surgery followed by radiation therapy leads to survival rates similar to those provided by total mastectomy, quality of life outcomes are much better $[6,7]$. Due to underrepresentation of elderly women and those with co-morbidities in RCTs, however, the risk/benefit balance of adjuvant radiotherapy after BCS is less clear as age increases. Therefore, a patient-inclusive decision among the treatment options is strongly recommended whenever possible by practice guidelines. It is also known that adherence to guidelines is often far from optimal and that several patient and health care characteristics may impair full implementation of these key recommendations [8].

The aim of our population-based study was to identify potential sources of variability in the primary treatment of breast cancer, with particular attention to time trends and to geographical, social, clinical, and hospital characteristics, using a validated monitoring system based on administrative databases.

\section{Methods}

\section{Studied population}

Incident breast cancer cases were identified in the regional resident population from the Piedmont Health Information System from January 1, 2000, to December 31, 2004.

All hospital discharge records (HDR), with a surgical Diagnosis Related Group and a code for breast cancer (International classification of diseases 9th revision-clinical modification, ICD9-CM) of 174, or in situ carcinoma of the breast, 233.0, in any position, were identified $(n=18,014)$. A small number of patients without a valid fiscal identification number were excluded $(n=50)$.

Prevalent cases (those having previous hospital admissions with any breast cancer code from 1995 on) were excluded from the analysis $(n=976)$. Patients with distant metastases at diagnosis $(n=966)$ were also excluded. Incident early breast cancer cases were then linked to the RT outpatient record database. All record linkages relied on the fiscal identification number.

\section{Endpoints}

The primary endpoint of the study is the type of initial treatment. Incident cases were classified, according to the initial treatment, into three groups: (a) Breast Conserving
Surgery (ICD9-CM: 85.2, 85.20-85.25, 85.12) followed within 9 months by radiation therapy $(\mathrm{BCS}+\mathrm{RT}$, $n=7,403$ ); (b) BCS without radiation therapy (BCS w/o $\mathrm{RT}, n=3,252$ ); and c) mastectomy (ICD9-CM: 85.33$85.49, n=5,367)$.

Patients undergoing a second surgical procedure within 5 months of the first operation $(n=1,303)$ were considered in the analysis according to the most recent type of treatment.

The BCS + RT group has been defined as women who underwent BCS with a subsequent adjuvant radiation therapy (RT) within 9 months after surgery. They were used as a common reference group with whom to compare the BCS w/o RT and mastectomy groups.

Exploratory subgroup analyses (by age, co-morbidity, and marital status) were performed to assess the presence of possible effect modifications.

Since the caseload and specialization of hospitals represented a strong predictor for type of treatment, patient characteristics associated with the choice of hospital responsible for the first surgical procedure were also analyzed.

\section{Data validation}

The accuracy of the method adopted to identify incident breast cancer cases was validated using data from the Piedmont Cancer Registry as a gold standard [9]. The algorithm was defined to obtain a high positive predictive value (i.e., the proportion of women that we defined as incident cases using administrative data that confirmed by the cancer registry).

To assess the endpoint accuracy, we validated the information based on administrative data with the information from clinical records of a sample of 512 women aged 50-69 years, randomly selected from the same population and treated during the first half of the year 2002 . For each case, we retrieved and abstracted all clinical records of any hospitalization identified from the HDR (2001-2005) and entered the data into a clinical audit database (QT Audit system) [10].

\section{Patient characteristics}

Patient characteristics included in the analysis were: age, education, marital status, tumor stage, and co-morbidity. Other variables included: year of admission, hospital volume of surgical breast procedures, and distance of patient's residence from nearest radiotherapy service.

Marital status was defined as married and unmarried (single, separated, divorced, or widowed).

Using all the diagnosis codes on the HDR for the first surgical admission ( $\max$ slots $=6$ ), the Disease Staging 
criteria [11] were used to classify patients into two broad categories according to absence (stage 1) or presence (stage 2) of nodal involvement.

The Charlson co-morbidity index, as adapted by Romano et al. [12] for use with ICD9-CM diagnoses from claims data, was implemented.

Piedmont hospitals were classified according to yearly average volume of breast cancer surgical procedures into four categories: less than 50, 50-99, 100-149, and equal to or greater than 150 cases. All extra-regional hospitals were grouped into a separate category.

The distance between the patient's residence and the nearest RT facility was considered as a measure of accessibility. The time required to cover the distances between all the towns of Piedmont, by car and under normal traffic conditions [13], was applied to each case. Four categories were defined: $<15,<30,<45$, and $>=45 \mathrm{~min}$.

In the analysis of predictors for the hospital chosen for surgery, we considered as "reference hospitals", hospitals that treat at least 150 new cases per year. All these reference hospitals were also equipped with RT and oncology services and were organized with dedicated multidisciplinary teams. In this analysis, the distance between a patient's residence and the nearest reference hospital was considered.

\section{Statistical analysis}

The association between the set of patient and hospital characteristics and the type of primary treatment was analyzed using a multinomial logistic regression model with robust estimates of standard error to adjust for hospital clusters. The results, expressed as odds ratios (OR) and
$95 \%$ confidence intervals $(95 \% \mathrm{CI})$, estimate how much the analyzed variables increased or reduced the probability of receiving either BCS without $\mathrm{RT}$ or mastectomy in comparison to $\mathrm{BCS}+\mathrm{RT}$ (the common reference group). Subgroup analyses by age ( $<70$ vs. $\geq 70)$, co-morbidity (absence vs. presence of one or more), and marital status were performed by stratification. A standard logistic regression model was used to study the association between patient characteristics and the type of first hospital, comparing reference hospitals (with more than 150 cases/year) with less specialized ones. Statistical analyses were performed using STATA (version 9.2) statistical software.

\section{Results}

During the 5-year period, 16,022 incident breast cancer cases were identified among women residing in the Piedmont region, $1,361(8.5 \%)$ of which were admitted at hospitals outside the region.

Figure 1 describes the initial pattern of care received by the whole cohort of women with newly diagnosed breast cancer.

The characteristics of the entire cohort, by type of treatment, are presented in Table 1. Associations between these same characteristics and type of treatment received are shown in Table 2 .

\section{Type of treatment}

Overall, the mean age of patients was 62 years $(\mathrm{SD}=13.4)$; women in the $\mathrm{BCS}+\mathrm{RT}$ were younger
Fig. 1 Initial pattern of care received by 16,022 women with a newly diagnosed case of early breast cancer. Piedmont region, 2000-2004

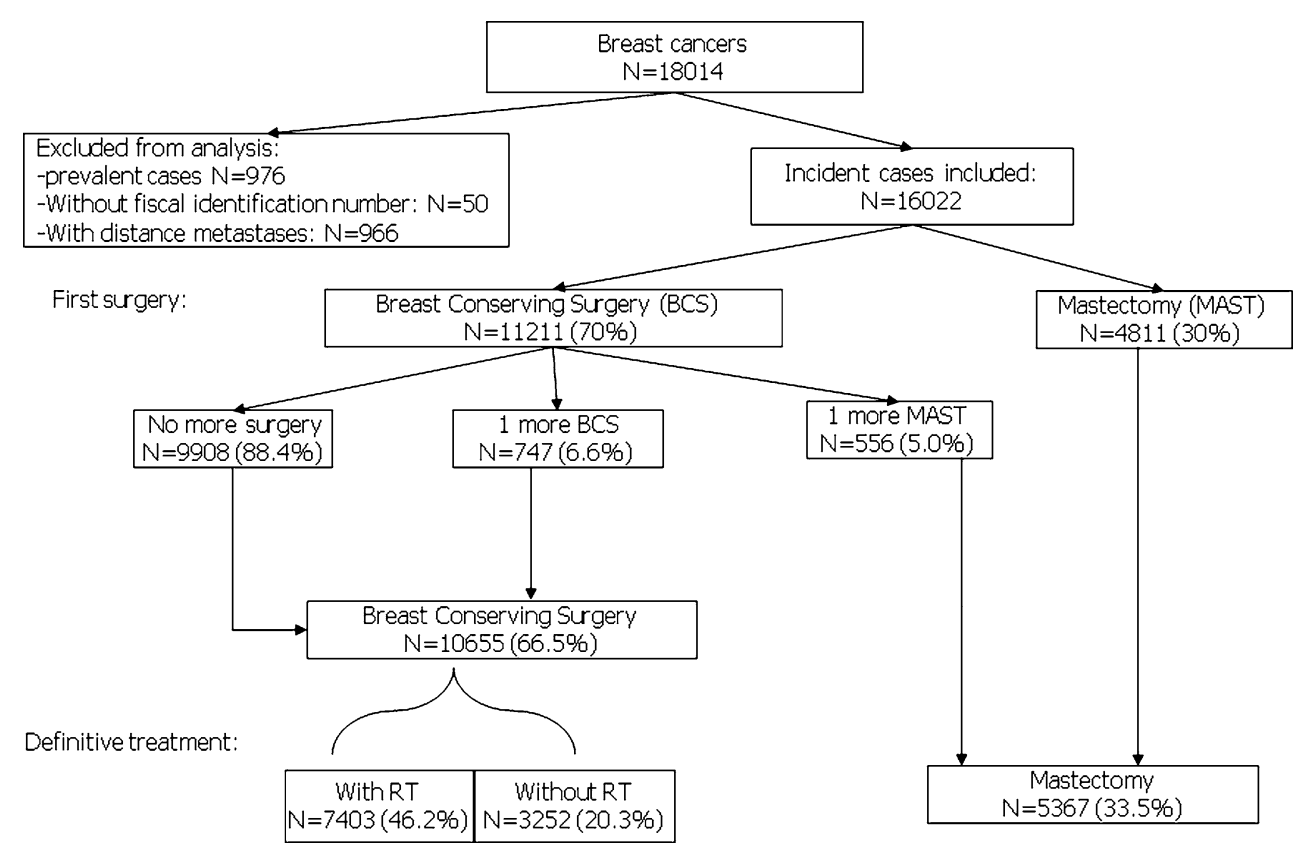


Table 1 Descriptive analysis of patient and healthcare system characteristics by type of treatment: Breast Conserving Surgery with RT (BCS + RT), BCS without RT (BCS w/o RT) and Mastectomy in 16,022 incident cases of early breast cancer

\begin{tabular}{|c|c|c|c|c|}
\hline & $\begin{array}{l}\text { Total } \\
(N=16,022)\end{array}$ & $\begin{array}{l}\text { BCS w/o RT } \\
(N=3,252)(\%)\end{array}$ & $\begin{array}{l}\text { Mastectomy } \\
(N=5,367)(\%)\end{array}$ & $\begin{array}{l}\mathrm{BCS}+\mathrm{RT} \\
(N=7,403)(\%)\end{array}$ \\
\hline \multicolumn{5}{|l|}{ Age } \\
\hline$<50$ & 3,219 & 18.5 & 17.8 & 22.5 \\
\hline $50-59$ & 3,601 & 20.3 & 16.9 & 27.5 \\
\hline $60-69$ & 4,259 & 22.8 & 21.9 & 31.6 \\
\hline $70-79$ & 3,679 & 23.3 & 30.5 & 17.4 \\
\hline$\geq 80$ & 1,264 & 15.2 & 12.9 & 1.0 \\
\hline \multicolumn{5}{|l|}{ Education level } \\
\hline Secondary or more & 2,894 & 16.5 & 16.1 & 20.2 \\
\hline Intermediate & 4,070 & 22.6 & 22.3 & 28.9 \\
\hline Primary & 6,806 & 43.1 & 48.1 & 38.1 \\
\hline Unknown & 2,252 & 17.8 & 13.4 & 12.9 \\
\hline \multicolumn{5}{|l|}{ Marital status } \\
\hline Married & 9,215 & 50.3 & 51.1 & 65.4 \\
\hline Not married & 5,133 & 35.9 & 39.8 & 24.7 \\
\hline Unknown & 1,674 & 13.9 & 9.1 & 9.9 \\
\hline \multicolumn{5}{|l|}{ Disease staging } \\
\hline Without nodal involvement & 14,039 & 92.7 & 82.1 & 89.3 \\
\hline With nodal involvement & 1,983 & 7.3 & 17.8 & 10.7 \\
\hline \multicolumn{5}{|l|}{ Charlson index } \\
\hline 0 & 14,803 & 91.9 & 90.1 & 94.3 \\
\hline$\geq 1$ & 1,219 & 8.1 & 9.9 & 5.7 \\
\hline \multicolumn{5}{|l|}{ Year of admission } \\
\hline 2000 & 3,115 & 18.7 & 20.7 & 18.8 \\
\hline 2001 & 3,047 & 18.1 & 19.9 & 18.8 \\
\hline 2002 & 3,186 & 20.1 & 20.5 & 19.4 \\
\hline 2003 & 3,272 & 21.0 & 20.0 & 20.5 \\
\hline 2004 & 3,402 & 22.1 & 18.9 & 22.5 \\
\hline \multicolumn{5}{|l|}{ Hospital volume $\left(N^{\mathrm{a}}\right)$} \\
\hline$\geq 150$ (5) & 4,958 & 28.0 & 24.7 & 36.7 \\
\hline 100 to $<150$ & 2,793 & 11.2 & 18.8 & 19.2 \\
\hline 50 to $<100(10)$ & 3,670 & 26.3 & 23.4 & 21.1 \\
\hline$\leq 50(63)$ & 3,235 & 20.9 & 25.8 & 15.8 \\
\hline Unknown $^{\mathrm{b}}(128)$ & 1,366 & 13.7 & 7.3 & 7.2 \\
\hline \multicolumn{5}{|l|}{ Distance to RT (min.) } \\
\hline Same city & 5,244 & 30.1 & 29.3 & 36.4 \\
\hline 0 to $<15$ & 2,563 & 15.6 & 15.2 & 16.7 \\
\hline 15 to $<30$ & 5,770 & 35.6 & 38.5 & 34.4 \\
\hline 30 to $<45$ & 1,684 & 12.1 & 11.7 & 9.0 \\
\hline$\geq 45$ & 761 & 6.8 & 5.4 & 3.4 \\
\hline
\end{tabular}

Piedmont region, 2000-2004

a Number of hospitals

b Extra-regional hospitals (mean $=58.77 \pm 11.3)$ than those in the BCS w/o RT group $(64.1 \pm 14.8)$ or in the mastectomy group $(64.8 \pm 14.3)$. At least one co-morbidity included in the Charlson index was recoded in $7.6 \%$ of cases, with a higher prevalence among the mastectomy groups (9.9\%). The most frequent co-morbidity included in the Charlson index are: Diabetes (3.11\%), other neoplasm (2.02\%) and chronic pulmonary diseases $(1.42 \%)$. Of the 16,022 incident cases, $5,367(33.5 \%)$ received a mastectomy, 7,403 (46.2\%) received $\mathrm{BCS}+\mathrm{RT}$, and 3,252 (20.3\%) received BCS w/o RT. Incomplete treatment (BCS w/o RT) was $18.1 \%$ and $25.3 \%$ in women below 70 and $70+$ years respecting.

Table 2 presents the adjusted ORs for receiving a mastectomy or BCS without RT compared to BCS + RT, according to patient and hospital characteristics. Elderly patients were more likely to have a mastectomy compared to women younger than 50 . The probability of receiving a mastectomy was also higher for unmarried individuals, 
Table 2 Association between type of treatment and patient and healthcare system characteristics by type of treatment: BCS without RT (BCS w/o RT) and mastectomy vs. BCS with RT (reference group) in 16,022 incident cases of early breast cancers

. Piedmont region, 2000-2004

a Screening age group (50-69): OR $(95 \% \mathrm{CI})$

BCS w/o: $0.91(0.80-1.03)$

Mastectomy: $0.81(0.72-0.91)$

b Number of hospitals

${ }^{c}$ Extra-regional hospitals

\begin{tabular}{|c|c|c|c|c|}
\hline & \multicolumn{2}{|c|}{ BCS w/o RT } & \multicolumn{2}{|c|}{ Mastectomy } \\
\hline & OR & $95 \% \mathrm{CI}$ & OR & $95 \% \mathrm{CI}$ \\
\hline \multicolumn{5}{|l|}{ Age } \\
\hline$<50$ & 1 & & 1 & \\
\hline $50-59^{\mathrm{a}}$ & 0.92 & $0.80-1.05$ & 0.78 & $0.70-0.88$ \\
\hline $60-69^{\mathrm{a}}$ & 0.89 & $0.77-1.02$ & 0.83 & $0.73-0.95$ \\
\hline $70-79$ & 1.54 & $1.29-1.85$ & 1.90 & $1.52-2.38$ \\
\hline$\geq 80$ & 16.39 & $12.06-22.26$ & 12.50 & $9.86-17.77$ \\
\hline \multicolumn{5}{|l|}{ Educational status } \\
\hline Secondary or more & 1 & & 1 & \\
\hline Intermediate & 0.94 & $0.81-1.09$ & 0.91 & $0.80-1.04$ \\
\hline Primary & 1.00 & $0.82-1.22$ & 1.03 & $0.89-1.20$ \\
\hline Unknown & 1.14 & $0.85-1.52$ & 1.10 & $0.84-1.44$ \\
\hline \multicolumn{5}{|l|}{ Marital status } \\
\hline Married & 1 & & 1 & \\
\hline Not married & 1.24 & $1.13-1.36$ & 1.33 & $1.19-1.48$ \\
\hline Unknown & 1.32 & $1.09-1.59$ & 1.04 & $0.81-1.32$ \\
\hline \multicolumn{5}{|l|}{ Disease staging } \\
\hline Without nodal involvement & 1 & & 1 & \\
\hline With nodal involvement & 0.65 & $0.56-0.76$ & 2.28 & $1.83-2.85$ \\
\hline \multicolumn{5}{|l|}{ Charlson index } \\
\hline 0 & 1 & & 1 & \\
\hline$\geq 1$ & 1.32 & $1.10-1.58$ & 1.45 & $1.20-1.76$ \\
\hline \multicolumn{5}{|l|}{ Year of admission } \\
\hline 2000 & 1 & & 1 & \\
\hline 2001 & 0.95 & $0.82-1.09$ & 0.93 & $0.81-1.07$ \\
\hline 2002 & 0.97 & $0.82-1.15$ & 0.92 & $0.74-1.14$ \\
\hline 2003 & 0.95 & $0.79-1.13$ & 0.83 & $0.66-1.04$ \\
\hline 2004 & 0.88 & $0.73-1.07$ & 0.70 & $0.56-0.88$ \\
\hline \multicolumn{5}{|l|}{ Hospital volume $\left(N^{\mathrm{b}}\right)$} \\
\hline$\geq 150(5)$ & 1 & & 1 & \\
\hline 100 to $<150$ (4) & 0.65 & $0.45-0.94$ & 1.22 & $0.78-1.89$ \\
\hline 50 to $<100(10)$ & 1.40 & $1.07-1.82$ & 1.47 & $1.01-2.14$ \\
\hline$\leq 50(63)$ & 1.31 & $1.07-1.60$ & 1.99 & $1.43-2.76$ \\
\hline Unknown $^{\mathrm{c}}(128)$ & 2.20 & $1.76-2.74$ & 1.20 & $0.88-1.63$ \\
\hline \multicolumn{5}{|l|}{ Distance to RT (min.) } \\
\hline Same city & 1 & & 1 & \\
\hline 0 to $<15$ & 1.20 & $1.03-1.40$ & 1.18 & $0.96-1.45$ \\
\hline 15 to $<30$ & 1.14 & $0.98-1.33$ & 1.31 & $1.12-1.54$ \\
\hline 30 to $<45$ & 1.35 & $1.10-1.65$ & 1.39 & $1.11-1.74$ \\
\hline$\geq 45$ & 1.75 & $1.39-2.20$ & 1.66 & $1.13-2.24$ \\
\hline
\end{tabular}

those with nodal involvement, co-morbidity, as well as with decreasing hospital caseload per year $(P$ for trend $<0.001)$ and increasing distance from residence to the nearest RT service ( $P$ for trend $<0.001$ ). In particular, patients who lived more than $45 \mathrm{~min}$ away from a RT service have a $70 \%$ increase in probability of receiving a mastectomy.
After adjustment for all other factors, education did not show any greater association with type of treatment. The main confounders of this crude association were age and type of hospital. The frequency of mastectomy significantly reduced during the 5 -year period ( $P$ for trend $<0.001$ ).

After adjustment for other variables, the probability of receiving BCS not followed by adjuvant RT was higher for 
older women, unmarried individuals, and in the presence of co-morbidity with increasing distance between residence and RT service ( $P$ for trend $<0.001$ ), for hospitals with a lower workload ( $<100$ cases) and for extra-regional hospitals. There was no meaningful effect of education level on type of treatment. During the period 2000-2004, there was a tendency toward a reduction in incomplete treatments even if the trend is not statistically significant $(P=0.280)$. Patients were less likely to undergo a BCS without RT in the presence of loco-regional disease.

Compared to younger women, those in the 50-69 screening age group were at lower risk of both BCS w/o RT $(0.91 ; 0.80-1.03)$ and mastectomy $(0.81 ; 0.72-0.91)$.

Stratified analyses by age $(<70$ vs. $\geq 70)$, comparing BCS w/o RT vs. BCS + RT did not indicate any effect modification for most variables (data not shown in tables). The probability of not receiving RT after BCS, increased markedly with age only after 70 years $(\mathrm{OR}=1.22$ per year; $95 \% \mathrm{CI}=1.20-1.25)$ and in the presence of comorbidity $(1.64 ; 1.18-2.27)$. For patients in the younger age group $(<70)$, neither age $(0.99 ; 0.99-1.00)$ nor comorbidity $(1.01 ; 0.80-1.29)$ showed any effect. Corresponding age-stratified analyses comparing mastectomy vs. $\mathrm{BCS}+\mathrm{RT}$ did not indicate any effect modification apart from age $(1.17 ; 1.15-1.19$ in the $70+$ age group vs. 0.99 ; 0.99-1.00 below 70 years).

Stratified analyses by co-morbidity (none vs. one or more) and marital status did not suggest any relevant effect modification.

\section{Choice of hospital}

Since the specialization of the hospital represented a strong predictor of the initial treatment, we explored the associations between patient characteristics and the choice of hospital. The probability of being treated at a reference hospitals (with a breast unit and a workload $\geq 150$ cases per year) decreased markedly with increasing age $(P$ for trend $<0.001)$ and distance between residence and these hospitals ( $P$ for trend $<0.0001$ ). On the contrary, the presence of co-morbidity $(1.22 ; 1.04-1.43)$ and advanced stage cancer (2.64; 2.30-3.02) were factors increasing the probability of access to reference hospitals. A reduced probability of admission to specialized hospitals was observed in women with primary $(0.73 ; 0.64-0.83)$ or intermediate education $(0.77 ; 0.68-0.87)$ with respect to those with secondary or a higher level of education.

\section{Data validation}

The algorithm used to identify incident breast cancers through the HDRs compared to the Cancer Registry had a positive predictive value of $92.6 \%(95 \% \mathrm{CI}=90.5-94.4)$ and a sensitivity of $76.7 \%$ (95\% CI $=73.8-79.4)$ [9].

HDRs for identifying BCS, compared to clinical data from a random sample of 512 patients, had a sensitivity of $95.5 \%(95 \% \mathrm{CI}=93.0-97.1)$ and a specificity of $98.2 \%$ (95\% CI $=93.6-99.5)$.

HDRs and RT outpatients records, used to identify postoperative RT, had a sensitivity of $87.4 \% \quad(95 \%$ $\mathrm{CI}=83.5-90.5)$ and $\mathrm{a}$ specificity of $94.4 \% \quad(95 \%$ $\mathrm{CI}=89.7-97.0)$.

\section{Discussion}

The most notable result of our study is that, at a population level, about one in five women did not receive an appropriate initial treatment due to a lack of adjuvant radiotherapy after breast-conserving surgery. Factors mainly responsible for this under-treatment were not only patient characteristics (e.g., increasing age, living alone, or presence of co-morbidities) but also health care features, such as being treated by hospitals with a low level of specialization and living in places with difficult access to radiotherapy facilities. The initial treatment of breast cancer did not seem directly influenced by other social factors such as education level.

Differences in the treatment of breast cancer by age were well documented in the literature, with older women less frequently receiving a high standard of care and possibly being exposed to worse outcomes [14]. While the importance of adjuvant RT after BCS is well documented [15], the under-representation of older women in RCTs makes it difficult to give strong, evidence-based recommendations for this age group [16]. Also, the ratio between BCS and mastectomy tends to decrease with age despite evidence of better quality of life after conservative surgery in elderly patients [17]. Several factors have been considered as possible explanations for the substandard treatment of elderly women, including ageism, advanced tumor stage, co-morbidity, short life expectancy, greater uncertainty in the risk-benefit calculation for treatments, individual preferences, and cultural or social barriers to accessibility [14]. The perceived value of breast conservation instead of mastectomy may be lower for older breast cancer patients, and the scientific evidence of a favorable benefit-to-risk balance for adjuvant radiotherapy is controversial. Therefore, the final decision should be made together with the patient after a careful multidimensional assessment $[16,17]$.

As expected, cases with nodal involvement had an increased probability of receiving definitive treatments, either mastectomy or BCS + RT [18], while the presence 
of one or more co-morbidities was negatively associated with adjuvant radiotherapy.

The lower probability of unmarried women with breast cancer receiving a definitive therapy is not new and has been interpreted as an effect of reduced family support and weaker social networks [19].

Previous studies have shown that certain socioeconomic factors such as ethnicity, income, insurance coverage, and education level are strong predictors of quality of care [20] and outcome [21].

At first, a crude association between education level and a lower probability of BCS + RT was evident, but this association was not present when other patient and hospital characteristics were accounted for. A more detailed analysis of the data revealed, however, that less educated women were more likely to be treated at hospitals with lower levels of specialization and, indirectly, were more likely to receive suboptimal treatments. Indeed, in our data, the association between hospital characteristics and the type of initial treatment is quite clear. Women treated in hospitals with an annual workload of $\leq 50$ cases had higher probability of receiving a non definitive treatment or mastectomy than women admitted to hospitals with more than 150 cases operated per year. Positive associations between a higher level of hospital caseload or specialization and BCS + RT have already been reported [22, 23]. In addition, lower local recurrence rates and improved survival for women who undergo surgery at a hospital with a high case volume have been documented [23]. These favorable results have been attributed to a mix of factors more frequently present in specialized centers: surgeons with greater experience and the presence of breast care units with a dedicated multidisciplinary team. As documented in other studies exploring the relationship between surgery volume and outcomes, the possibility of selection bias cannot be ruled out [24].

Another factor strongly influencing the pattern of care received by early breast cancer cases is the distance between the patient's residence and the closest radiotherapy service. In line with previous studies, mainly conducted in the USA [25], we noted a significant decrease in the probability of receiving breast radiation treatments after a conservative procedure for women living at greater distances from RT services. The geographic accessibility to RT facilities is confirmed to be a barrier for continuity of care, independent of other patient characteristics. Also, women receiving BCS in extra-regional hospitals showed significantly reduced access to RT, likely due to difficulties in warranting continuous care in healthcare migrations. This is likely to be due to lower levels of completeness in data from other regions, the database for outpatient RT has been previously analyzed in depth and provided reliable results with a high level of completeness [26].
During the period analyzed, the probability of receiving a mastectomy, and possibly a non-definitive treatment, shows a negative trend. This large-scale effect may be a consequence of the diffusion and implementation of regional guidelines in the cancer care network, but other factors, such as progressive regional coverage by the screening program protocol, may have played a role as well. In the presence of a national tendency towards reducing the number of mastectomy procedures and increasing radiotherapy after BCS [27], it is fundamentally impossible to distinguish the effects of local initiatives from general trends with observational studies.

The recent reorganization of cancer care into a regional network with dedicated multidisciplinary teams and the introduction of regional, evidence-based guidelines for the most common cancers points out the need for an efficient system to monitor the quality of care and to measure the impact of this new organization system.

Generally, cancer registries are considered the best candidate to measure the quality of cancer care at the population level [28], but cancer registries generally may not have detailed clinical information (as stage, co-morbidity and treatment).

Our study has both strengths and limitations. First, we developed and validated an algorithm to identify incident breast cancer cases [9] and validated the endpoint analyzed with a random sample of medical records. Second, the study is population-based and minimize selection bias of predictors of cancer treatment such as geographic, regional, urban vs. rural location, and socioeconomic status [29]. Third, we were able to adjust for several important covariates, both at the patient and healthcare system levels. The main weakness in our study, similar to that of other studies relying on administrative data, is the lack of detailed clinical information, as tumor size, multi-centricity and co-morbidity, which could partially explain the observed undertreatment especially in elderly cases [30].

In conclusion, our results show that inequalities still exist in access to appropriate breast cancer therapies in a setting characterized by both a national health system and a regional cancer network. The monitoring system that we applied, based on administrative data, allowed confirmation of the specific role of certain determinants of inequality independently from individual patient characteristics and the health care system. Future initiatives should also consider social and geographical factors in addition to hospital specialization to reduce the incidence of inappropriate care for breast cancer.

Acknowledgment This study was supported by the Compagnia di San Paolo, the M.I.U.R./PRIN grant 2005068001 and the Eunice project of the European Commission. The regional program of guideline development and quality assessment has been also supported by: Piedmont Region-Regional Health Authority; Fondazione 
CRT-DI7 Project; Ministry of Health-Research Programm exart 12bis DL 229/99, 2006.

\section{References}

1. Iezzoni LI (1997) Assessing quality using administrative data. Ann Intern Med 127:666-674

2. Kahn KL, Malin JL, Adams J, Ganz PA (2002) Developing a reliable, valid, and feasible plan for quality-of-care measurement for cancer: how should we measure? Med Care 40:73-85

3. Regione Piemonte Assessorato Sanità, Commissione Oncologica Regionale, Centro di Riferimento per l'Epidemiologia e la Prevenzione Oncologica in Piemonte. (2002) Tumore della mammella - linee guida clinico organizzative per la Regione Piemonte

4. Nattinger AB (2003) Quality of care for breast cancer. Med Care $41: 341-343$

5. Malin JL, Schuster MA, Kahn KA, Brook RH (2002) Quality of breast cancer care: what do we know? J Clin Oncol 20:43814393

6. Fisher B, Jeong JH, Anderson S, Bryant J, Fisher ER, Wolmark N (2002) Twenty-five-year follow-up of a randomized trial comparing radical mastectomy, total mastectomy, and total mastectomy followed by irradiation. N Engl J Med 347:567-575

7. Veronesi U, Cascinelli N, Mariani L, Greco M, Saccozzi R, Luini A et al (2002) Twenty-year follow-up of a randomized study comparing breast-conserving surgery with radical mastectomy for early breast cancer. N Engl J Med 347:1227-1232

8. Grol R, Grimshaw J (2003) From best evidence to best practice: effective implementation of change in patients' care. Lancet 362:1225-1230

9. Baldi I, Vicari P, Di Cuonzo D, Zanetti R, Pagano E, Rosato R et al (2008) A high positive predictive value algorithm using hospital administrative data identified incident cancer cases. J Clin Epidemiol 61:373-379

10. Ponti A, Segnan N, Blamey R, Bordon R, Cataliotti L, Codd M et al (2001) Data collection on treatment of screen-detected lesions. In: European Commision EACP (ed) European guidelines for quality assurance in mammography screening, 3rd edn. European Commission Publication, Luxembourg

11. Gonnella JS, Hornbrook MC, Louis DZ (1984) Staging of disease. A case-mix measurement. JAMA 251:637-644

12. Romano PS, Roos LL, Jollis JG (1993) Adapting a clinical comorbidity index for use with ICD-9-CM administrative data: differing perspectives. J Clin Epidemiol 46:1075-1079

13. IRES Piemonte (2004) Matrix of distances between Piedmont towns. Distributed by: Servizio di Epidemiologia-ASL 5. Collana Banca Dati, Issue 10

14. Bouchardy C, Rapiti E, Blagojevic S, Vlastos AT, Vlastos G (2007) Older female cancer patients: importance, causes, and consequences of undertreatment. J Clin Oncol 25:1858-1869

15. Clarke M, Collins R, Darby S, Davies C, Elphinstone P, Evans E, Godwin J, Gray R, JS Hicks C, MacKinnon E, McGale P, McHugh T, Peto R, Taylor C, Wang Y, Group EBCTC (2005) Effects of radiotherapy and of differences in the extent of surgery for early breast cancer on local recurrence and 15-year survival: an overview of the randomised trials. Lancet 366:2087-2106

16. Wildiers H, Kunkler I, Biganzoli L, Fracheboud J, Vlastos G, Bernard-Marty C et al (2007) Management of breast cancer in elderly individuals: recommendations of the International Society of Geriatric Oncology. Lancet Oncol 8:1101-1115

17. de Haes JC, Curran D, Aaronson NK, Fentiman IS (2003) Quality of life in breast cancer patients aged over 70 years, participating in the EORTC 10850 randomised clinical trial. Eur J Cancer 39:945-951

18. Morrow M, Goldstein L (2006) Surgery of the primary tumor in metastatic breast cancer: closing the barn door after the horse has bolted? J Clin Oncol 24:2694-2696

19. Osborne C, Ostir GV, Du X, Peek MK, Goodwin JS (2005) The influence of marital status on the stage at diagnosis, treatment, and survival of older women with breast cancer. Breast Cancer Res Treat 93:41-47

20. Polacek GN, Ramos MC, Ferrer RL (2007) Breast cancer disparities and decision-making among U.S. women. Patient Educ Couns 65:158-165

21. Bradley CJ, Given CW, Roberts C (2002) Race, socioeconomic status, and breast cancer treatment and survival. J Natl Cancer Inst 94:490-496

22. Hoffmann J (2006) Analysis of surgical and diagnostic quality at a specialist breast unit. Breast (Edinburgh, Scotland) 15:490-497

23. Stefoski Mikeljevic J, Haward RA, Johnston C, Sainsbury R, Forman D (2003) Surgeon workload and survival from breast cancer. Br J Cancer 89:487-491

24. Nattinger AB, Laud PW, Sparapani RA, Zhang X, Neuner JM, Gilligan MA (2007) Exploring the surgeon volume outcome relationship among women with breast cancer. Arch Int Med 167:1958-1963

25. Schroen AT, Brenin DR, Kelly MD, Knaus WA, Slingluff CL Jr (2005) Impact of patient distance to radiation therapy on mastectomy use in early-stage breast cancer patients. J Clin Oncol 23:7074-7080

26. Pagano E, Di Cuonzo D, Bona C, Baldi I, Gabriele P, Ricardi U et al (2007) Accessibility as a major determinant of radiotherapy underutilization: a population based study. Health Policy 80:483491

27. Zorzi M, Puliti D, Vettorazzi M, De Lisi V, Falcini F, Federico M et al (2006) Mastectomy rates are decreasing in the era of service screening: a population-based study in Italy (1997-2001). Br J Cancer 95:1265-1268

28. Malin JL, Keeler E, Wang C, Brook R (2002) Using cost-effectiveness analysis to define a breast cancer benefits package for the uninsured. Breast Cancer Res Treat 74:143-153

29. Gilligan MA, Kneusel RT, Hoffmann RG, Greer AL, Nattinger AB (2002) Persistent differences in sociodemographic determinants of breast conserving treatment despite overall increased adoption. Med Care 40:181-189

30. Velanovich V, Gabel M, Walker EM, Doyle TJ, O'Bryan RM, Szymanski W et al (2002) Causes for the undertreatment of elderly breast cancer patients: tailoring treatments to individual patients. J Am Coll Surg 194:8-13 